Check for updates

Cite this: RSC Adv., 2018, 8, 32200

\title{
Photosensitizer-loaded biomimetic platform for multimodal imaging-guided synergistic phototherapy $\dagger$
}

\author{
Ying Tian,,$^{\mathrm{ab}}$ Ying Zhao, $\dot{t}^{\mathrm{a}}$ Wenfei Liu, ${ }^{\mathrm{c}}$ Ying Liu, ${ }^{\mathrm{a}}$ Yuxia Tang, ${ }^{\mathrm{a}}$ Zhaogang Teng, (D) ad \\ Chunni Zhang, ${ }^{\star a b}$ Shouju Wang*ad and Guangming Lu (D)*ad
}

Photodynamic therapy (PDT) has attracted much attention as a strategy for tumor therapy. However, the insolubility and poor tumor-targeting ability of most photosensitizers (PSs) hinder PDT from further development. Therefore, it is necessary to explore new carriers with good water solubility and biocompatibility to deliver PSs to tumors. Melanin nanoparticles are novel biomimetic nanocarriers with excellent biocompatibility, loading capacity, photothermal therapy (PTT) and magnetic resonance (MR)/ photoacoustic (PA) imaging properties. Here we designed polydopamine melanin nanoparticles (PDMNs) as a delivery platform for the photosensitizer Chlorin e6 (PDMN-Ce6) and realized its application as a theranostic agent for tumor therapy. The PDMN-Ce6 exhibited excellent biocompatibility, good water solubility and high loading capability (35.2 wt\%) for Ce6. Compared with the free Ce6, PDMN-Ce6 showed higher cellular internalization and superior synergistic phototherapy effects in an in vitro study. An in vivo study indicated that the accumulation of PDMN-Ce6 at tumor sites was 2.8-fold higher than that of free $\mathrm{Ce} 6$ at $24 \mathrm{~h}$ post-injection, which was beneficial for MR/PA imaging. Moreover, the synergetic therapy significantly inhibited tumor growth, causing tumor necrosis and tumor angiogenesis suppression. These results suggest that our biomimetic and biocompatible platform could improve the delivery of $\mathrm{Ce} 6$ to tumors and realize multimodal imaging-guided tumor synergetic phototherapy.

Received 31st May 2018

Accepted 17th August 2018

DOI: $10.1039 / c 8 r a 04663 h$

rsc.li/rsc-advances as PS carriers for PDT, with good solubility, tumor-targeting ability and biocompatibility. ${ }^{6-8}$

At present, metallic nanocarriers with diverse structures, controllable sizes, flexible surface modification, tumortargeting and theranostic abilities have emerged as attractive tools for PS delivery. ${ }^{9-12}$ However, the complicated synthesis and long-term toxicity of these nanocarriers may limit their translation potential. ${ }^{13}$ For example, gold nanoparticles eliminate slowly from the liver and spleen; it is reported that the vast assemblies of gold particles may persist in liver and spleen for one year post-injection. ${ }^{14}$ This slow excretion of nanoparticles from the body raises great concerns about their potential longterm toxicity. Thus, it is essential to develop a delivery platform with better biocompatibility and biodegradability. ${ }^{15-17}$

Polydopamine melanin nanoparticles (PDMNs) are an emerging kind of biomimetic polymer, which keep the natural characteristics of melanin pigment, such as its excellent biocompatibility, water solubility and biodegradability. ${ }^{18}$ PDMNs can be applied for photothermal therapy (PTT) due to their high photothermal conversion efficacy. ${ }^{19,20}$ They also exhibit high binding efficiencies with aromatic molecules via $\pi-$ $\pi$ stacking interactions. ${ }^{21,22}$ Since most PSs have aromatic groups, PDMNs might be utilized as a multifunctional PS carrier. It has recently been reported in the literature that PDMNs could be used as a carrier of Chlorin e6 (Ce6) for PDT 


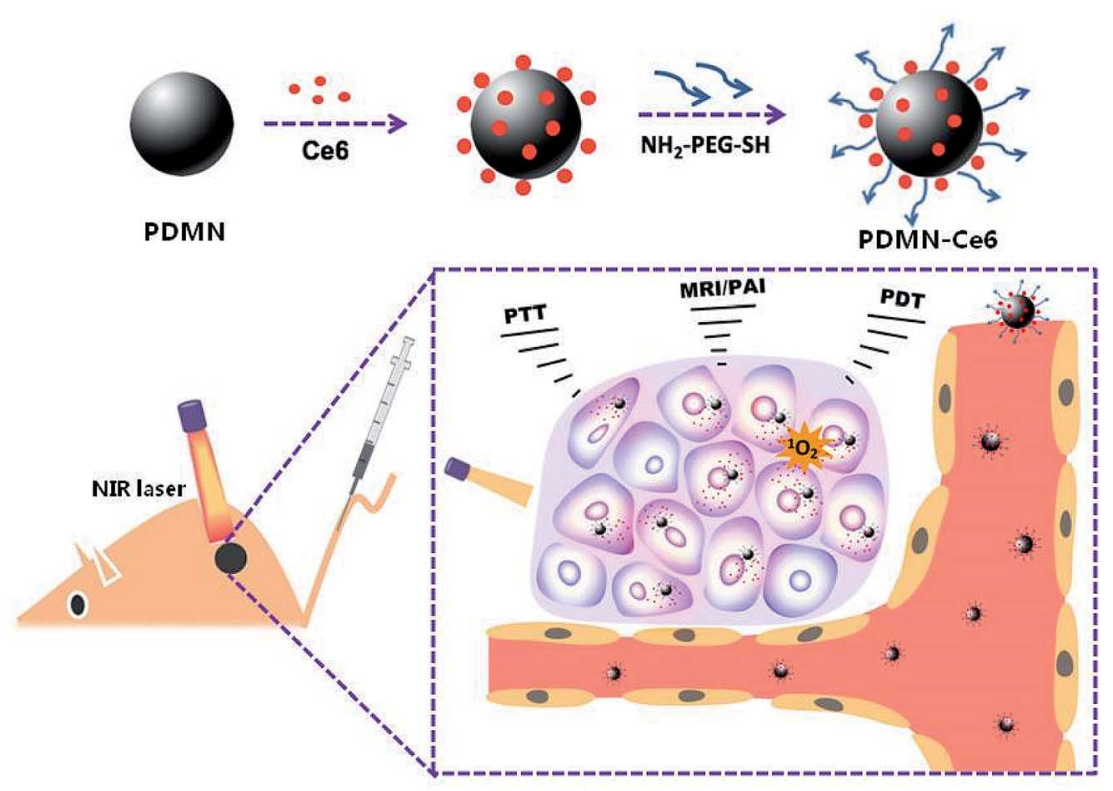

Scheme 1 Schematic illustration of the synthesis and application of the biomimetic platform PDMN-Ce6 for MRI/PAI-guided synergistic phototherapy.

and PTT. ${ }^{23}$ Furthermore, PDMNs are suitable for magnetic resonance imaging (MRI) and photoacoustic imaging (PAI). ${ }^{24-26}$ However, to the best of our knowledge, in vivo multimodal imaging guided-synergistic phototherapy of PDMNs as PS carriers has not been reported.

Herein, we synthesized PDMNs by the self-polymerization method. ${ }^{27}$ The PDMNs were then modified by polyethylene glycol (PEG), loaded with the photosensitizer Ce6, and termed as PDMN-Ce6. This novel loading platform showed high Ce6 loading capacity, excellent biocompatibility, low off-target toxicity, and preferable tumoral accumulation. Moreover, the in vivo results demonstrated that PDMN-Ce6 could induce synergistic PDT/PTT under MRI/PAI guidance, which significantly inhibited tumor growth and tumor angiogenesis (Scheme 1).

\section{Materials and methods}

\subsection{Materials}

Dopamine hydrochloride, ammonia aqueous solution $\left(\mathrm{NH}_{4} \mathrm{OH}\right.$, 28-30\% wt\%), Chlorin e6 (Ce6) and cell uptake inhibitors (nocodazole, cytochalasin $\mathrm{D}$, chlorpromazine, genistein, and $\beta$ cyclodextran) were purchased from Sigma-Aldrich (Shanghai, China). 3-(4,5-Dimethylthiazol-2-yl)-2,5-diphenyltetrazolium bromide (MTT) was provided by KeyGEN Biotech. Co., Ltd. (Jiangsu, China). Amine-PEG-thiol $\left(\mathrm{NH}_{2}\right.$-PEG-SH, $\mathrm{MW} \approx 2000$ Da) was obtained from Laysan Bio. Inc. (Shanghai, China). Singlet oxygen sensor green (SOSG) kits were purchased from Invitrogen (Shanghai, China). Human breast tumor cells (SKBR3) and human mammary epithelial cells (MCF 10A) were purchased from ATCC (Manassas, VA). Fetal bovine serum (FBS), trypsin, media and phosphate buffered saline (PBS) were purchased from Gibco/Life Technologies (Shanghai, China).

\subsection{Synthesis of PDMNs and PDMN-Ce6}

Polydopamine melanin nanoparticles were prepared by a selfpolymerization synthesis method. In brief, about $0.6 \mathrm{~mL}$ $\mathrm{NH}_{4} \mathrm{OH}(28-30 \%)$ was added into ethanol $(8 \mathrm{~mL})$ and deionized water $(18 \mathrm{~mL})$ and the solution was placed in a water bath at $30{ }^{\circ} \mathrm{C}$ and stirred gently for $30 \mathrm{~min}$. Then, dopamine hydrochloride $(100 \mathrm{mg}$ ) dissolved in $2 \mathrm{~mL}$ deionized water was injected into the solution and it was stirred for another 12$24 \mathrm{~h}$. The color of the solution turned from pale yellow to dark black. Ce6 was then added to the produced melanin nanoparticles. In short, different concentrations of Ce6 were added into solutions as prepared above, and mixed in the dark for about $12 \mathrm{~h}$. Then, all the product solutions were purified by centrifugation at $15000 \mathrm{rpm}$ for $10 \mathrm{~min}$. Finally, $0.5 \mathrm{~mL}$ amine-PEG-thiol ( $\mathrm{NH}_{2}$-PEG-SH, $2 \mathrm{mM}$ ) was injected into each solution to prepare PEGylated PDMNs in alkaline buffer solution $(\mathrm{pH}=9)$ by continuous stirring for $24 \mathrm{~h}$. The products were also purified by centrifugation at $15000 \mathrm{rpm}$ for $10 \mathrm{~min}$ and dispersed in water. The PEGylated melanin nanoparticles without or with Ce6 loading were termed PDMN and PDMNCe6, respectively.

\subsection{Characterization}

The spherical morphology and sizes of PDMN were first observed by transmission electron microscopy (TEM, JEOL JEM2100, Japan). The absorbance spectra of Ce6, PDMN, and PDMN-Ce6 were tested using a UV-Vis spectrometer (Lambda 35, PerkinElmer, USA). The Ce6, PDMN and PDMN-Ce6 were further characterized by Fourier transform infrared (FT-IR) spectroscopy (Nicolet NEXUS870, Nicolet Instruments Inc. Madison, USA). The hydrodynamic diameters of PDMN and PDMN-Ce6 were determined using a ZetaPALS analyzer 
(Brookhaven, USA). The diameter changes of PDMN-Ce6 dispersed in PBS and FBS were measured for 15 days to estimate its stability.

\subsection{The loading capacity}

To test the loading capacity of PDMN, we mixed different weight ratios of PDMN (1 mg) and Ce6 $(0.325,0.075,0.125,0.5$ and 1 $\mathrm{mg}$ ), and stirred the mixtures for $12 \mathrm{~h}$. Then, the unconjugated Ce6 in the supernatants were collected through washing and centrifugation, and quantified using a UV calibration curve at $404 \mathrm{~nm}$. The weight of Ce6 was estimated according to a standard curve. Thereafter, the final binding capacity of Ce6 to the surface of PDMN through $\pi-\pi$ stacking was calculated according to the following equation: (weight of total Ce6 - weight of free Ce6)/ (weight of total Ce6 - weight of free Ce6 + weight of PDMN).

\subsection{Photodynamic and photothermal properties}

The generation of singlet oxygen from Ce6, PDMN, PDMN-Ce6 and PDMN + Ce6 (the mixture of Ce6 and PDMN) was determined from the fluorescence signals of SOSG, following the manufacturer's instructions. To test the PTT properties, $1 \mathrm{~mL}$ samples of equal concentrations of Ce6, PDMN, and PDMN-Ce6 dispersed in water were irradiated with a $660 \mathrm{~nm}$ wavelength laser (Hi-Tech Optoelectronics Co., Ltd., China) to test their temperature variations at a power density of $1 \mathrm{~W} \mathrm{~cm} \mathrm{~cm}^{-2}$. A control of $1 \mathrm{~mL}$ of deionized water was used. To further investigate photostability, $1 \mathrm{~mL}$ of PDMN-Ce6 was exposed to the laser at a power density of $1 \mathrm{~W} \mathrm{~cm}^{-2}$ for five ON-OFF cycles (ON, $5 \mathrm{~min}$; OFF, $7 \mathrm{~min}$ ). The corresponding temperature changes during laser irradiation were monitored in real time using an infrared camera (MAGNITY f15F1, Wuhan VST Light \& Technology Co., Ltd., China).

\subsection{MR and PA imaging in vitro}

For MR and PA imaging, different concentrations $(0,0.1,0.5,1$ and $4 \mathrm{mg} \mathrm{mL}^{-1}$ ) of PDMN-Ce6 were put into tubes and scanned using a 7.0 T micro-MRI instrument (PharmaScan, Bruker Biospin GmbH, Germany) and a multispectral photoacoustic tomography imaging system (iThera Medical inVision 256-TF, Germany) at a wavelength of $660 \mathrm{~nm}$.

\subsection{Cell culture and cellular uptake}

Human breast tumor cells (SKBR-3) and human mammary epithelial cells (MCF 10A) were cultured in media with $1 \%$ penicillin/streptomycin and $10 \% \mathrm{FBS}$, and under a $5 \% \mathrm{CO}_{2}$ atmosphere at $37{ }^{\circ} \mathrm{C}$, according to the ATCC's protocol. When the confluence of SKBR-3 cells reached $70 \%$, cells were incubated with PDMN-Ce6 $\left(200 \mu \mathrm{g} \mathrm{mL}^{-1}\right)$ or Ce6 $\left(50 \mu \mathrm{g} \mathrm{mL}{ }^{-1}\right.$, corresponding to the loading capacities and products of PDMN) for $4 \mathrm{~h}, 8 \mathrm{~h}$, and $24 \mathrm{~h}$. Then, cells were rinsed, collected, and resuspended in PBS. In addition, to investigate the concentration impacts on cellular uptake, SKBR-3 cells were incubated with $50 \mu \mathrm{g} \mathrm{mL}{ }^{-1}, 100 \mu \mathrm{g} \mathrm{mL} \mathrm{m}^{-1}$ or $200 \mu \mathrm{g} \mathrm{mL} \mathrm{m}^{-1}$ of PDMN-Ce6 for $24 \mathrm{~h}$. Cells were collected after incubation for flow cytometry testing. Untreated cells were taken as the control. All the fluorescent signals from Ce6 were recorded using an Accuri C6 flow cytometer (CytoFLEX, Beckman Coulter, USA) and analyzed by Flowjo 7. SKBR-3 cells were further collected and observed by confocal microscopy after incubation with the PDMN-Ce6 (100 $\mu \mathrm{g} \mathrm{mL}^{-1}$ ) for $24 \mathrm{~h}$.

\subsection{Cellular uptake pathway}

The cellular uptake pathway was evaluated by incubation with cell uptake inhibitors, ${ }^{28}$ including nocodazole $\left(10 \mu \mathrm{g} \mathrm{mL}{ }^{-1}\right)$, cytochalasin D $\left(10 \mu \mathrm{g} \mathrm{mL}{ }^{-1}\right)$, chlorpromazine $\left(10 \mu \mathrm{g} \mathrm{mL}{ }^{-1}\right)$, genistein $\left(10 \mu \mathrm{g} \mathrm{mL}^{-1}\right)$ and $\beta$-cyclodextran $\left(5 \mu \mathrm{g} \mathrm{mL}^{-1}\right)$. In short, SKBR-3 cells were incubated with the above inhibitors for $30 \mathrm{~min}$ at $37^{\circ} \mathrm{C}$. Then the cells were washed, fresh media containing $200 \mu \mathrm{g} \mathrm{mL}{ }^{-1}$ of PDMN-Ce6 was added, and incubation was continued for $24 \mathrm{~h}$. A cell sample treated at $4{ }^{\circ} \mathrm{C}$ was maintained at $4{ }^{\circ} \mathrm{C}$ after the medium was replaced. Untreated cells were taken as a control. After that, the cell samples were collected and the fluorescent signals were traced by flow cytometry.

\subsection{Cell viability assay}

Human breast tumor cells (SKBR-3) and human mammary epithelial cells (MCF 10A) were seeded in 96-well plates. When the confluence of cells reached about $70 \%$, they were incubated with PDMN or PDMN-Ce6 using the same concentration gradient $\left(0,1,2,4,8 \mathrm{mg} \mathrm{mL} \mathrm{mL}^{-1}\right)$ without irradiation. After $24 \mathrm{~h}$ incubation, cells were washed three times, and the cell viabilities were tested by MTT assay. To evaluate the synergetic effect of PDT and PTT, SKBR-3 cells cultured in 96-well plates were incubated with the PDMN, PDMN-Ce6 (0, 12.5, 25, 50 and 100 $\mu \mathrm{g} \mathrm{mL}^{-1}$ ) or Ce6 for $24 \mathrm{~h}$. Then, cells were exposed to a $660 \mathrm{~nm}$ laser from a diode-pumped solid-state NIR laser system at a power density of $1.0 \mathrm{~W} \mathrm{~cm}^{-2}$ for $5 \mathrm{~min}$. Then the synergetic therapy efficiency was measured by MTT assay after treatments. The material toxicity after incubation was further tested using LIVE/DEAD viability/cytotoxicity kits following the manufacturer's instructions.

\subsection{Biodistribution}

All procedures involving animals were approved by the Institutional Animal Care and Use Committee of Jinling hospital (Nanjing, China). This study was performed in strict accordance with the NIH guidelines for the care and use of laboratory animals (NIH publication no. 85-23 Rev. 1985). Approximately 5 $\times 10^{6}$ SKBR-3 cells were subcutaneously injected into the right flank of female nude mice to establish breast tumor animal models. Mice were chosen and divided into two groups $(n=12$ / group) when their tumor sizes reached about $100 \mathrm{~mm}^{3}$. The two groups were injected intravenously with $100 \mu \mathrm{L}$ of $3 \mathrm{mg} \mathrm{mL}$

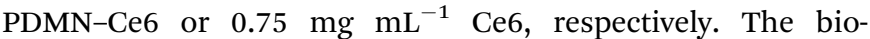
distribution was observed after dissection using an animal optical imaging system (IVIS Lumina XR, Caliper, USA) at different time points $(0,1,4,8$ and $24 \mathrm{~h})$ after injection. The fluorescence signals from Ce6 (excitation: $640 \mathrm{~nm}$, emission: $705 \mathrm{~nm}$ ) were captured and quantified using Living Image Software. 


\subsection{MR/PA imaging in vivo}

When the breast tumor animal models were established, mice were chosen randomly for intravenous injection with $100 \mu \mathrm{L}$ of $3 \mathrm{mg} \mathrm{mL}{ }^{-1}$ PDMN-Ce6. Then mice were investigated by MR and PA imaging using the 7.0-T micro-MRI instrument and the multispectral photoacoustic tomography imaging system, respectively, at a time point $24 \mathrm{~h}$ after injection. The imaging signals were captured and analyzed using imaging software for each mouse.

\subsection{Photothermal effect in vivo}

Tumor-bearing mice $(n=4)$ were injected intravenously with $100 \mu \mathrm{L}$ of PBS or $100 \mu \mathrm{L}$ of $3 \mathrm{mg} \mathrm{mL}{ }^{-1}$ PDMN or PDMN-Ce6, or $100 \mu \mathrm{L}$ of $0.75 \mathrm{mg} \mathrm{mL}^{-1} \mathrm{Ce} 6$. Twenty-four hours after injection, mice were anesthetized and then exposed to a $660 \mathrm{~nm}$ wavelength near infrared (NIR) laser at a power density of $1 \mathrm{~W} \mathrm{~cm}^{-2}$ for $5 \mathrm{~min}$. The temperature changes in the tumors were monitored using a MAGNITY f15F1 infrared camera.

\subsection{PDT and PTT in vivo}

SKBR-3 tumor-bearing mice were divided into four groups $(n=$ 5/group). The four groups were injected intravenously with 100 $\mu \mathrm{L}$ of PBS, $100 \mu \mathrm{L}$ of $3 \mathrm{mg} \mathrm{mL}^{-1}$ PDMN or PDMN-Ce6, or $100 \mu \mathrm{L}$ of $0.75 \mathrm{mg} \mathrm{mL}^{-1} \mathrm{Ce} 6$, and then irradiated with a single laser at $1 \mathrm{~W} \mathrm{~cm}^{-2}$ for $5 \mathrm{~min}$, at a time point $24 \mathrm{~h}$ post-injection. The tumor volumes and body weights were measured every three days. The tumor volumes were calculated according to the equation: volume $=a \times b^{2} \times 0.5(a=$ greatest longitudinal diameter of the tumor, $b=$ greatest transverse diameter of the tumor).

\subsection{Histopathology}

After therapy in vivo, some important tissues were dissected and prepared for pathological sectioning, including the tumor, heart, liver, spleen, lung, and kidney. All the section specimens were stained with hematoxylin and eosin (H\&E). Besides, tumor specimens were further subjected to vascular immunohistochemical staining (IHC). The microvessel density (MVD) analysis was conducted according to Weidner using the IHC results. ${ }^{29}$ The counting regions of vessels should be different from the surrounding tumor cells and the connective tissue components, and brown stained endothelial cells or cell clusters acted as blood vessels, including branch structures but not including the vessels with muscular layers or lumens. The number of microvessels was recorded from three microscope views, and the average number was used as the tumor MVD.

\subsection{Blood indicators in vivo}

To further detect the biosafety of the preparations, mice were divided into two groups ( $n=12$ /group). Four mice in each group were chosen randomly for intravenous injection of $100 \mu \mathrm{L}$ of $3 \mathrm{mg} \mathrm{mL}{ }^{-1}$ PDMN, $100 \mu \mathrm{L}$ of $3 \mathrm{mg} \mathrm{mL}^{-1}$ PDMN-Ce6, or $100 \mu \mathrm{L}$ of $0.75 \mathrm{mg} \mathrm{mL}^{-1} \mathrm{Ce} 6$ (corresponding to the loading capacities and products of PDMN), respectively. Twenty-four hours after injection, the whole blood of one mice group was drawn to test biochemical indicators including aspartate aminotransferase (AST), alanine aminotransferase (ALT), alkaline phosphatase (ALP), blood urea nitrogen (BUN) and serum creatinine (SCr). Also, serum samples from another mice group were obtained to detect important routine blood indicators, including white blood cell (WBC) count, red blood cell (RBC) count, hemoglobin (HGB) quantification, and platelet (PLT) count.

\subsection{Hemolysis assay}

About $2 \mathrm{~mL}$ heparin-stabilized human blood was collected to study the blood compatibility of PDMN-Ce6. Blood was added into normal saline to obtain red blood cells (RBCs) by centrifugation at $2000 \mathrm{rpm}$ for $5 \mathrm{~min}$. Then, RBCs after washing were diluted with $10 \mathrm{~mL}$ of saline. After that, $0.2 \mathrm{~mL}$ of diluted RBC suspension was added into $0.8 \mathrm{~mL}$ saline with different concentrations of PDMN-Ce6, and maintained at $37{ }^{\circ} \mathrm{C}$ for $2 \mathrm{~h}$. As the positive and negative controls, $0.2 \mathrm{~mL}$ of diluted $\mathrm{RBC}$ suspension was added to $0.8 \mathrm{~mL}$ of water or saline, respectively. Finally, $0.1 \mathrm{~mL}$ of supernatant isolated from the mixtures by centrifugation at $2000 \mathrm{rpm}$ for $5 \mathrm{~min}$ was transferred into a 96well plate. The absorbance values were immediately measured at $490 \mathrm{~nm}$ using a microplate reader (infinite M200 PRO, TECAN, Switzerland). The hemolysis of RBCs (\%) was calculated using the following equation: $100 \times$ (absorbance of samples absorbance of negative control)/(absorbance of positive control - absorbance of negative control).

\subsection{Statistical analysis}

Statistical analysis was performed using the two-sided Student's $t$-test for two groups, and two-way analysis of variance for multiple groups using GraphPad Prism 6 (GraphPad Software Inc., CA, USA). Probabilities as $p<0.05\left(^{*}\right), p<0.01(* *)$, and no significance (n.s.) are marked in relevant figures.

\section{Results and discussion}

\subsection{Preparation and characterization}

PDMN was prepared according to the previous report ${ }^{27}$ and loaded with Ce6 on the surface through $\pi-\pi$ interactions, in order to realize delivery and synergetic therapy. It was then modified with PEG to prolong the blood circulation time and improve biocompatibility. The TEM images showed that the average diameter of PDMN was $\sim 100 \mathrm{~nm}$ and that the particles had spherical morphology (Fig. 1a). To confirm the successful loading of Ce6, UV-Vis, FT-IR and dynamic light scattering (DLS) measurements were obtained. The characteristic absorption peaks of Ce6 at $\sim 402 \mathrm{~nm}$ and $\sim 670 \mathrm{~nm}$ were found in the UV-Vis absorption spectrum of PDMN-Ce6 (Fig. 1b). The absorption peak of Ce6 at $2964 \mathrm{~cm}^{-1}$ (corresponding to $\mathrm{C}-\mathrm{H}$ vibrations) ${ }^{30,31}$ was also found in the FT-IR absorption spectrum of PDMN-Ce6 (Fig. 1c). Furthermore, as shown by the DLS measurements, the hydrodynamic diameter of PDMN increased from $146.2 \pm$ $2.1 \mathrm{~nm}$ to $161.1 \pm 3.6 \mathrm{~nm}$ after loading of Ce6 (Fig. 1d). Taken together, these results suggested that the Ce6 molecules were attached to the surface of PDNM after vigorous stirring. 


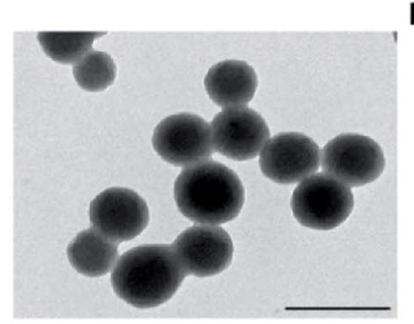

d

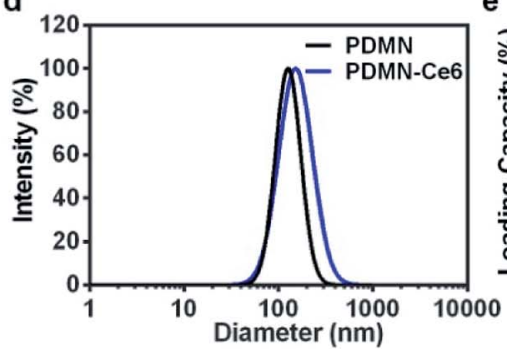

b

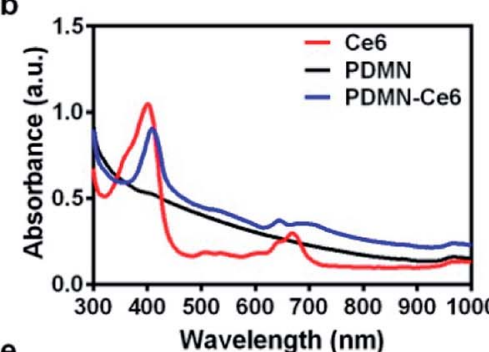

c

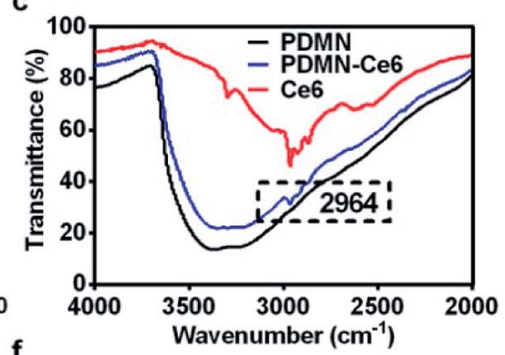

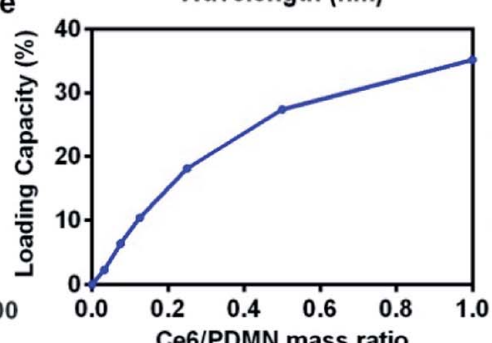

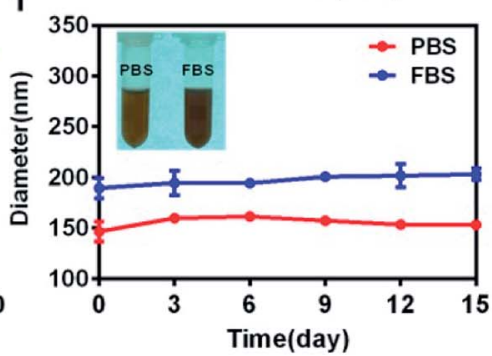

Fig. 1 (a) TEM image of PDMN; scale bar: $100 \mathrm{~nm}$. (b) UV-Vis spectra of Ce6, PDMN and PDMN-Ce6 from 300 to $1000 \mathrm{~nm}$. (c) FT-IR spectra of Ce6, PDMN and PDMN-Ce6. (d) The hydrodynamic diameters of PDMN and PDMN-Ce6. (e) The loading capacity of Ce6 on the PDMN. (f) The hydrodynamic diameters of PDMN-Ce6 in PBS or FBS for 15 days.

To further investigate the loading capacity of PDMN-Ce6, we prepared mixtures containing PDMN and different concentrations of Ce6. The amount of unconjugated Ce6 in the supernatants was quantified. As shown in Fig. 1e, the loading capacity of PDMN-Ce6 increased with increasing mass ratio of Ce6 : PDMN. When the mass ratio of Ce6 : PDMN reached $1: 1$, the maximum loading capacity peaked at $35.2 \mathrm{wt} \%$. This result indicated that PDMN had a high loading capacity for Ce6. The stability of the interactions between PDMN and Ce6 was then investigated. As shown in Fig. 1f, the size of PDMN-Ce6 dispersed in PBS or FBS was stable in a simulated physiological environment for up to 15 days. In addition, no fluorescence signals from free Ce6 were detected in the supernatant of PDMN-Ce6 solution after centrifugation, demonstrating that no free Ce 6 detached from the surface of PDMN after 15 days due to the strong interactions between the PDMN and the Ce6 molecules. Therefore, we supposed that the Ce6 molecules were connected to PDMN by $\pi-\pi$ stacking interactions rather than by much weaker adsorption forces (Fig. S1†).

\subsection{Photodynamic and photothermal properties}

To further evaluate the photochemical and photophysical properties, we investigated the ${ }^{1} \mathrm{O}_{2}$ production ability of PDMNCe6 by SOSG assay. As shown in Fig. 2a, the SOSG fluorescence signals of free Ce6, PDMN-Ce6 and PDMN + Ce6 increased rapidly upon laser irradiation, while no signal increase was detected in $\mathrm{H}_{2} \mathrm{O}$ or PDMN solution, implying that the ${ }^{1} \mathrm{O}_{2}$ generation capacity was from the $\mathrm{Ce} 6$ molecules rather than from PDMN. Compared with the free Ce6 at the same concentration, the ${ }^{1} \mathrm{O}_{2}$ production ability of PDMN-Ce6 was slightly lower, probably because some of the fluorescence signal from SOSG was absorbed by the PDMN-Ce6 itself.

To further investigate the photothermal properties, Ce6, PDMN, and PDMN-Ce6 were evaluated by irradiation with a $660 \mathrm{~nm}$ laser $\left(1 \mathrm{~W} \mathrm{~cm}^{-2}\right)$ for $5 \mathrm{~min}$. Deionized water was used as the control. As shown in Fig. $2 b$ and c, the temperature of PDMN and PDMN-Ce6 increased upon laser irradiation due to the strong photothermal conversion efficacy of melanin nanoparticles. Conversely, no significant temperature change was observed in $\mathrm{Ce} 6$ or $\mathrm{H}_{2} \mathrm{O}$ solutions. It was also noted that PDMNCe6 exhibited stable photothermal conversion after five ONOFF heating cycles (irradiation with $660 \mathrm{~nm}$ laser at $1.0 \mathrm{~W} \mathrm{~cm}^{-2}$ for $5 \mathrm{~min}$ and cooling for $7 \mathrm{~min}$ ), revealing its excellent photostability (Fig. 2d).

\subsection{MRI/PAI in vitro}

PDMN-Ce6 could be used as a novel MRI/PAI contrast agent with high resolution and strong specificity, due to the unique T1 shortening effect and high photothermal conversion efficacy of the melanin nanoparticles. The combination of MRI and PAI in one platform induced by the PDMN could be very helpful for precise diagnosis and better guidance for tumor treatment. As shown in Fig. 3a and b, the same concentration gradients of tube phantoms were subjected to MRI and PAI, respectively. The data indicated that the MRI and PAI intensities of PDMN-Ce6 increased in parallel as the concentration increased, and were linearly proportional to the concentration $\left(R^{2}=0.99\right)$. These results demonstrated the potential MRI and PAI applications of PDMN-Ce6.

\subsection{Cellular uptake and internalization pathway}

In order to test the cellular uptake, SKBR-3 cells were incubated with PDMN-Ce6 or Ce6 for $4 \mathrm{~h}, 8 \mathrm{~h}$ and $24 \mathrm{~h}$. The fluorescence signals of Ce6 were traced by flow cytometry. The fluorescence signals were consistent with the cellular uptake levels. From Fig. 4a, the cellular uptake of PDMN-Ce6 and Ce6 was dependent on the incubation time. Compared with cells treated with 
a

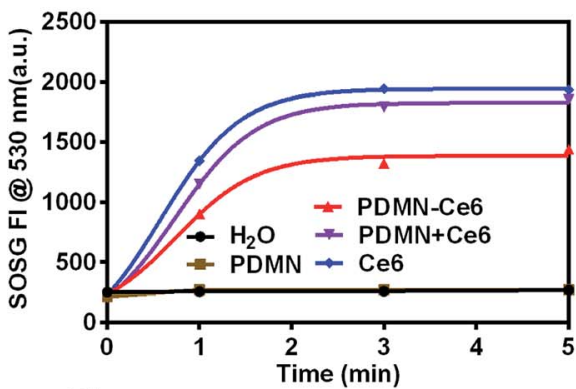

C

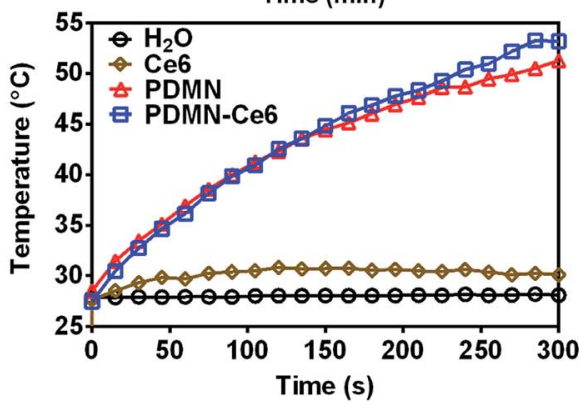

b
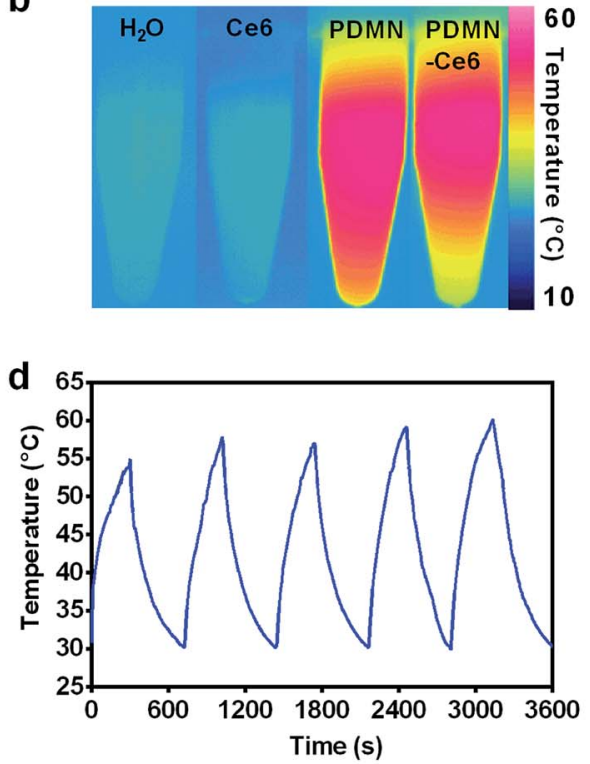

Fig. 2 (a) SOSG fluorescence intensity (FI) at $530 \mathrm{~nm}$ in $\mathrm{H}_{2} \mathrm{O}$, PDMN, PDMN-Ce6, PDMN + Ce6 and Ce6 under laser irradiation (660 nm, 1 W $\mathrm{cm}^{-2}, 5 \mathrm{~min}$ ). (b) Thermal images and (c) temperature curves of $\mathrm{H}_{2} \mathrm{O}, \mathrm{Ce} 6$, PDMN and PDMN-Ce6 at the same proportional concentrations under irradiation ( $660 \mathrm{~nm}$ laser, $1 \mathrm{~W} \mathrm{~cm}^{-2}, 5 \mathrm{~min}$ ). (d) Photostability of PDMN-Ce6 over five cycles of irradiation with a $660 \mathrm{~nm}$ laser at $1 \mathrm{~W} \mathrm{~cm}^{-2}$ for 5 min and cooling for $7 \mathrm{~min}$.

free Ce6 and untreated control cells, the cells incubated with PDMN-Ce6 exhibited increased cell internalization. As shown in Fig. $4 \mathrm{~b}$, the cellular uptake was also positively related to the incubation concentration of PDMN-Ce6. This indicated that the loading of $\mathrm{Ce} 6$ onto the PDMN may improve the cellular uptake of the PS and be beneficial to tumor treatment. Confocal microscopy analysis showed Ce6 signals after incubating cells with the PDMN-Ce6 $\left(100 \mu \mathrm{g} \mathrm{mL}^{-1}\right)$ for $24 \mathrm{~h}$ (Fig. S2 $\dagger$ ). The overlay images revealed that the fluorescence signals of Ce6 were from the cytoplasm of the cells, which further suggested that PDMN-Ce6 could enter into the tumor cells and deliver the photosensitizer into the cytoplasm.

The PDMN-Ce6 internalization pathway was then investigated. Cells were pretreated with several inhibitors before incubation with the PDMN-Ce6. As shown in Fig. 4c, PDMNCe6 internalization was inhibited by cytochalasin D (cell filamentous actin inhibitor) and $4{ }^{\circ} \mathrm{C}$ (energy blocker), and slightly influenced by nocodazole (microtubule disruptor), $\beta$-cyclodextran (lipid raft inhibitor), chlorpromazine (clathrin inhibitor) and genistein (protein tyrosine kinase inhibitor). This indicated that the cellular uptake of PDMN-Ce6 occurred mainly through a filamentous actin-driven and energydependent endocytosis.

\subsection{Cytotoxicity and cellular PDT/PTT efficacy}

Since the cell cytotoxicity is vital for the application of a drug delivery platform, the cell biocompatibility of SKBR-3 and MCF 10A with PDMN and PDMN-Ce6 was tested by MTT assay. After incubation for $24 \mathrm{~h}$ without laser irradiation, both the tumor cells and normal cells retained viabilities of higher than $90 \%$, even at the high PDMN and PDMN-Ce6 concentrations of $8 \mathrm{mg}$ $\mathrm{mL}^{-1}$ (Fig. 5a and b). The low toxicity was visually confirmed by LIVE/DEAD cell staining, as shown in Fig. S3. $\dagger$ Most cells were live (green); there were very few dead cells (red) after the incubation of the cells with PDMN-Ce6 at the concentration of $8 \mathrm{mg}$ $\mathrm{mL}^{-1}$ without laser treatment. These results indicated that PDMN and PDMN-Ce6 had low cytotoxicity and would be applicable for in vitro PDT and PTT.
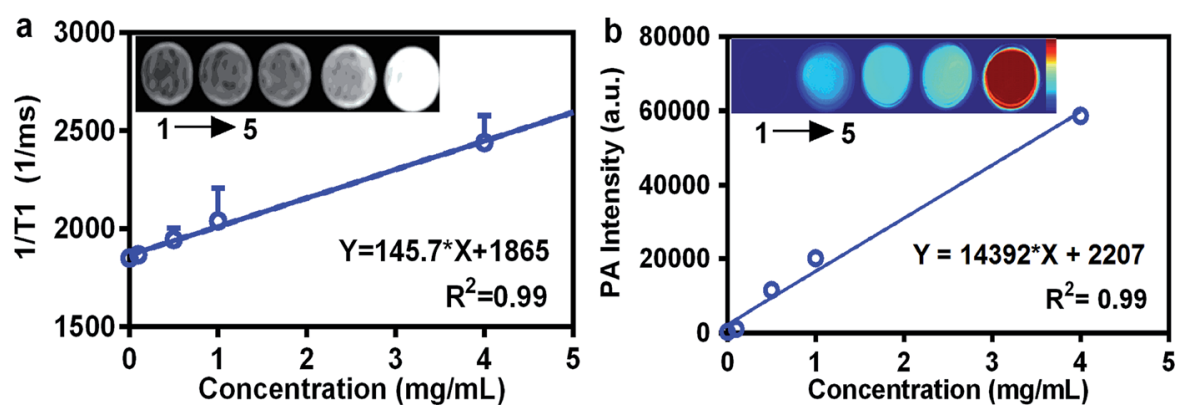

Fig. 3 (a) MRI images and plot of PDMN-Ce6 at different concentrations. (b) PAl images and plot of PDMN-Ce6 at different concentrations. The images from 1 to 5 correspond to the concentrations of $0,0.1,0.5,1$ and $4 \mathrm{mg} \mathrm{mL}^{-1}$, respectively. 

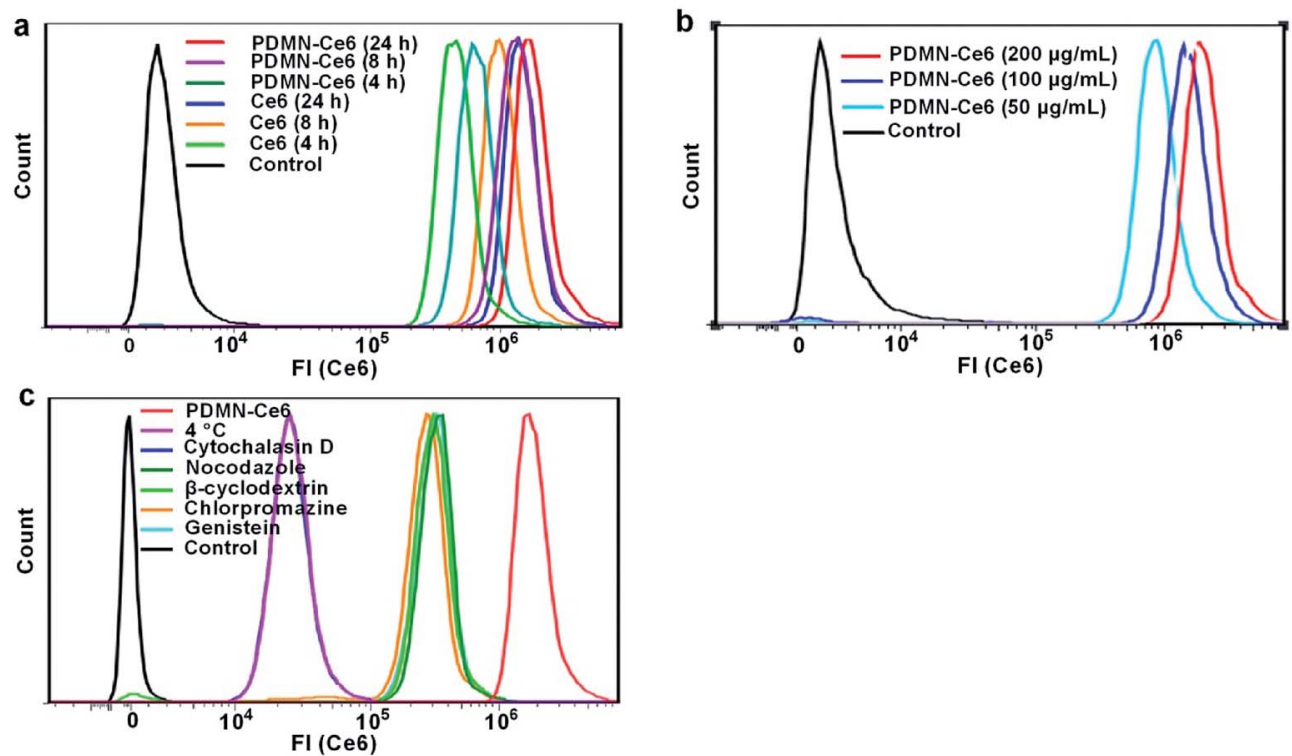

Fig. 4 (a) The degree of cellular uptake of PDMN-Ce6 and Ce6 (equal proportional concentrations) after incubation for $4 \mathrm{~h}, 8 \mathrm{~h}$ and $24 \mathrm{~h}$. (b) The degree of cellular uptake of different concentrations of PDMN-Ce6 after $24 \mathrm{~h}$. (c) Detection of the cellular internalization pathway by treatment of the cells with different cell inhibitors or culture at $4{ }^{\circ} \mathrm{C}$.

Next, the therapeutic effects against tumor cells were evaluated by MTT. SKBR-3 cells were treated with the same concentration gradients of Ce6, PDMN or PDMN-Ce6 for $24 \mathrm{~h}$, and then irradiated by a single laser $\left(660 \mathrm{~nm}, 1.0 \mathrm{~W} \mathrm{~cm}^{-2}, 5 \mathrm{~min}\right)$. As shown in Fig. 5c, the cell viability data indicated that there was a concentration-dependent therapeutic PDT/PTT effect. Compared with incubation with free Ce6 or PDMN, it was noted that PDMN-Ce6 exhibited superior therapeutic efficacy at the equivalent concentration. The viability of SKBR-3 cells incubated with PDMN-Ce6 decreased from $32 \%$ to lower than $11 \%$ as the concentration increased from $12.5 \mu \mathrm{g} \mathrm{mL} \mathrm{mL}^{-1}$ to $100 \mu \mathrm{g}$ $\mathrm{mL}^{-1}$. The much lower cell viability in the group treated with the PDMN-Ce6 was attributed to the high intracellular delivery of PDMN-Ce6 and effective synergetic therapy of PDT and PTT.

\subsection{Biodistribution and MRI/PAI in vivo}

Breast tumor mice models were established and injected intravenously with PDMN-Ce6 or $\mathrm{Ce} 6$ to trace the biodistribution of the nanoparticles. As shown in Fig. 6a, the distribution of PDMN-Ce6 at the tumor site $24 \mathrm{~h}$ post-injection was remarkably higher than that before intravenous injection, but there were few fluorescence signals exhibited in normal tissues. The calculation of the relative fluorescence intensities showed that the intensity in the tumor was 2.8 fold higher for PDMN-Ce6 than for free Ce6 at $24 \mathrm{~h}$ post-injection (Fig. $6 \mathrm{~b}$ ). Conversely, the intensities were strong in liver, lung and kidney after accumulation in mice injected with Ce6 (Fig. 6a and c). These results indicated that the anchoring of $\mathrm{Ce} 6$ on the PDMN not only reduced the potential toxicity but also increased the tumor-targeting of Ce6, which is favorable for tumor therapy in vivo.

Because PDMNs have received considerable attention in MRI and PAI, the potential for noninvasive imaging of PDMN-Ce6 in vivo was evaluated. Because the accumulations of PDMN-Ce6 at the tumor sites were at their maximum at $24 \mathrm{~h}$ post-injection, MRI and PAI were performed on SKBR-3 mice models before and $24 \mathrm{~h}$ after injection. As seen in Fig. 6d and e, the MRI and
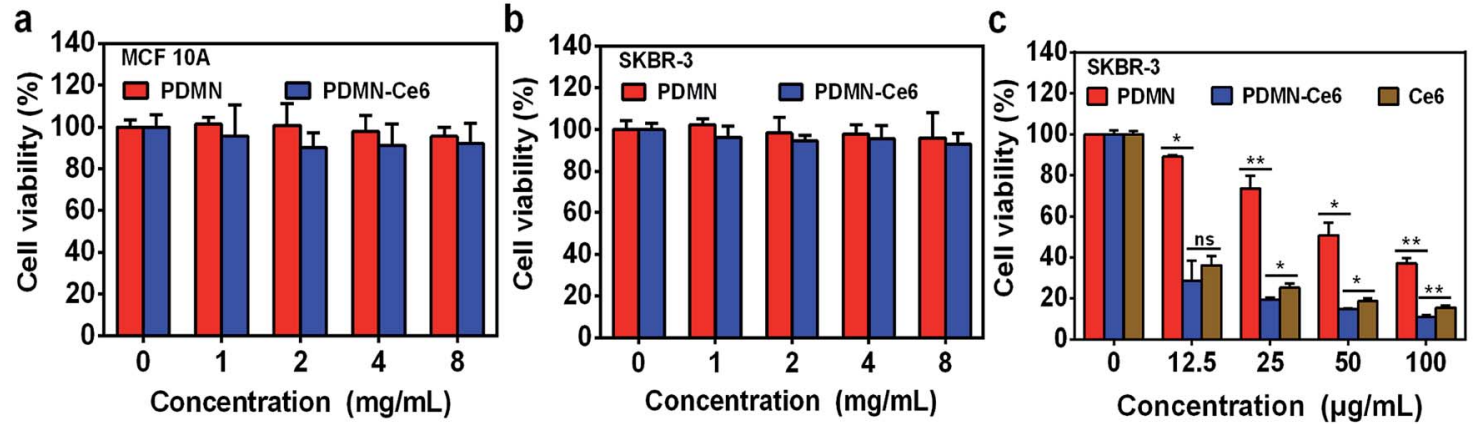

Fig. 5 (a) Relative cell viability of MCF $10 A$ and (b) SKBR-3 cells after incubation with PDMN or PDMN-Ce6 at different concentrations without irradiation. (c) Relative cell viability of SKBR-3 cells after incubation with PDMN, PDMN-Ce6 or Ce6 at different concentrations under irradiation $\left(660 \mathrm{~nm}, 1 \mathrm{~W} \mathrm{~cm}^{-2}, 5 \mathrm{~min}\right)$. Asterisk * indicates $p<0.05$; asterisks ** indicates $p<0.01$. 


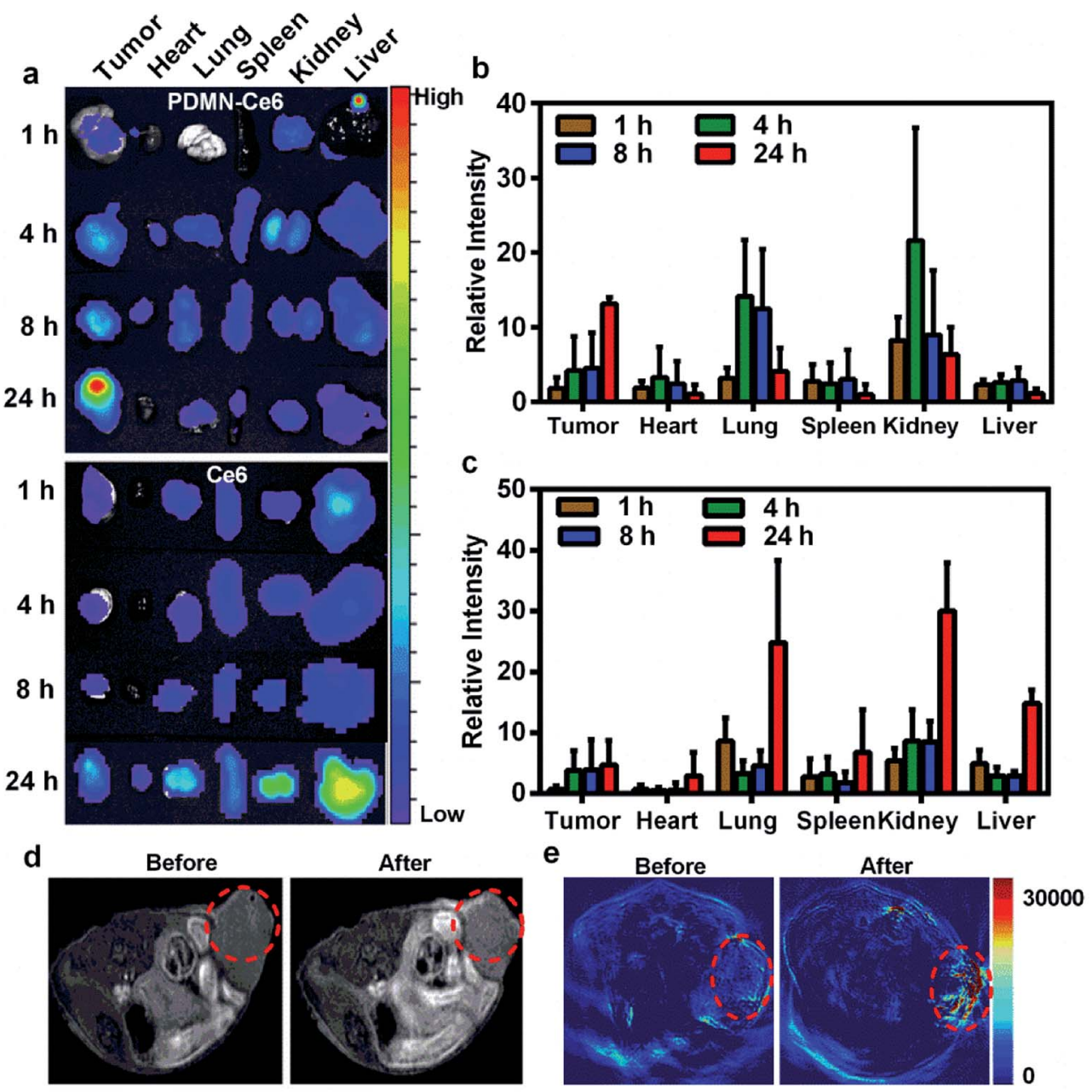

Fig. 6 (a) The biodistribution of PDMN-Ce6 and Ce6 at time points $1 \mathrm{~h}, 4 \mathrm{~h}, 8 \mathrm{~h}$ and $24 \mathrm{~h}$ after intravenous injection. The images were captured by the animal optical imaging system. (b) Relative fluorescence intensities at different time points of the main tissues of mice injected with PDMN-Ce6. (c) Relative fluorescence intensities at different time points of the main tissues of mice injected with Ce6. (d) MRI of mice before and $24 \mathrm{~h}$ after intravenous injection of PDMN-Ce6. (e) PAl of mice before and $24 \mathrm{~h}$ after intravenous injection of PDMN-Ce6. The red circles indicate the locations of the tumors.

PAI signal intensities of the tumor sites increased significantly with the accumulation of nanomaterials, compared with the sites before injection. The MRI/PAI results further indicated the excellent tumor targeting ability of PDMN-Ce6, which could be used in precise molecular imaging-guided tumor therapy.

\subsection{Photothermal effect and synergetic phototherapy efficiency in vivo}

To investigate the most effective PTT treatment with minimal side effects in vivo, tumor-bearing mice were injected intravenously with PBS, Ce6, PDMN or PDMN-Ce6, and then irradiated with a $660 \mathrm{~nm}$ wavelength laser at $1 \mathrm{~W} \mathrm{~cm}^{-2}$ for $5 \mathrm{~min}$ at a time point $24 \mathrm{~h}$ post-injection. The temperature changes were recorded during the treatment (Fig. 7a and b). The temperatures of the tumor sites increased by about 16 and 12 degrees in the groups treated with PDMN-Ce6 and PDMN, respectively, while an increase of only three degrees was observed in the group treated with Ce6. The PBS-treated group showed a negligible temperature change. Minimal skin injury was observed after laser irradiation, indicating that the PDMN-Ce6 induced PDT/ PTT treatment would not injure the normal skin tissues (Fig. S4†).

To further evaluate the synergetic therapy efficiency in vivo, tumor-bearing mice were divided into four groups and injected intravenously with PBS, Ce6, PDMN or PDMN-Ce6, respectively. Synergetic therapy was performed $24 \mathrm{~h}$ post-injection, under the guidance of MRI/PAI. As shown in Fig. 7c, tumor growth was more effectively inhibited in the PDMN-Ce6-treated group ( $p<$ 0.05) than in the groups treated with Ce6 or PDMN. Furthermore, the tumor volumes in the mice treated with PBS grew rapidly. Therefore, the PDMN-Ce6 exhibited a superior synergetic therapy effect in vivo.

After the treatments, H\&E staining and vascular IHC staining were carried out on tumors from each group. As shown in Fig. 8a, the tumors showed obvious coagulation necrosis after treatment accompanied by a reduced volume, particularly in the PDMN-Ce6 treatment group. Moreover, the synergetic therapy inhibited tumor blood vessels growing in the PDMN-Ce6 group. 
a
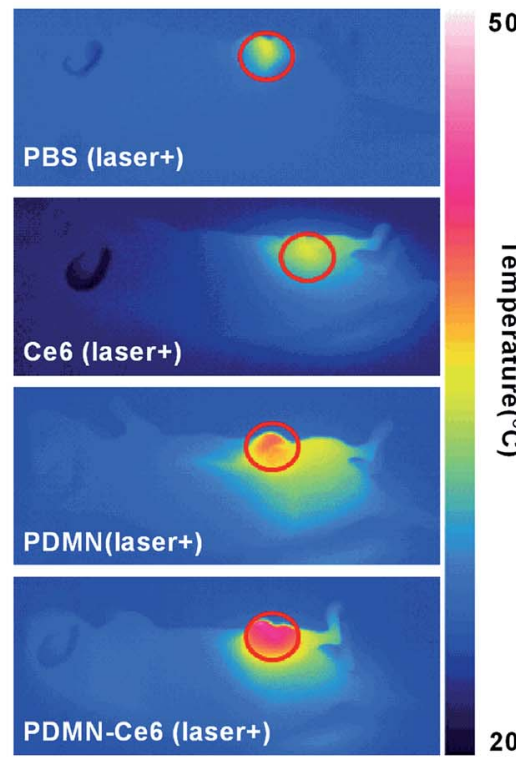

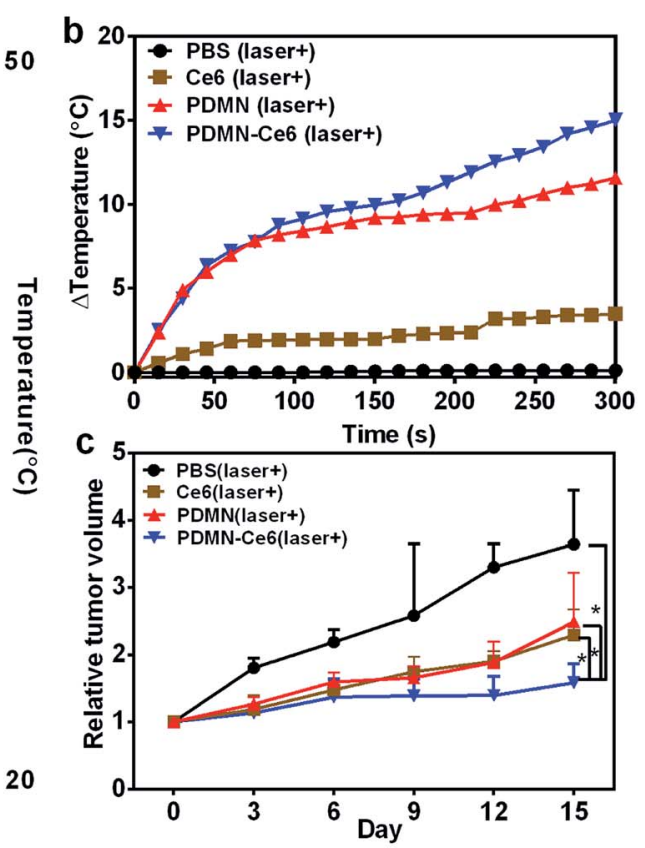

Fig. 7 (a) Representative thermal images of tumor-bearing mice after laser irradiation for $5 \mathrm{~min}\left(660 \mathrm{~nm}, 1 \mathrm{~W} \mathrm{~cm}^{-2}\right)$. (b) The tumor temperatures during the period of irradiation $\left(660 \mathrm{~nm}, 1 \mathrm{~W} \mathrm{~cm} \mathrm{~cm}^{-2}, 5 \mathrm{~min}\right)$ in mice treated with PBS, Ce6, PDMN and PDMN-Ce6 at a time point $24 \mathrm{~h}$ after injection. (c) Tumor growth curves of tumor-bearing mice after treatment. The tumor volumes were normalized to their initial sizes (asterisks indicate $p<0.05$ ).
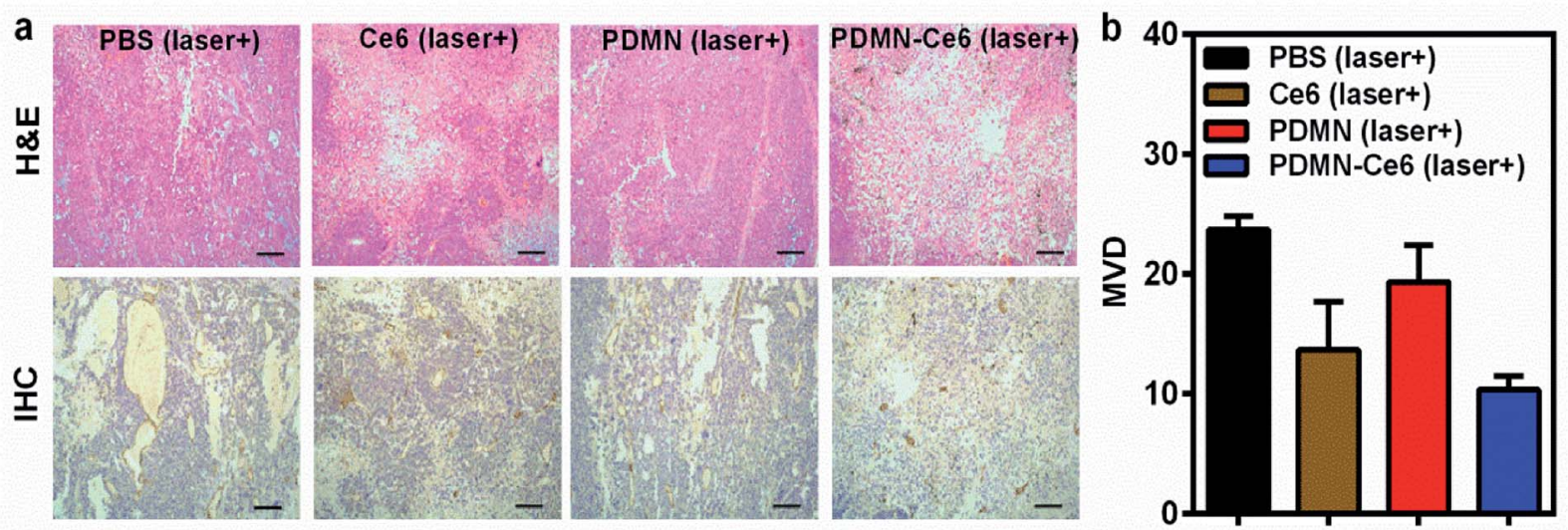

Fig. 8 (a) H\&E and IHC staining of tumors from each mice group after treatment; scale bars: $100 \mu \mathrm{m}$. (b) The microvessel density (MVD) of tumors in the different mice groups after treatment.

The microvessel density (MVD) in each group is displayed in Fig. 8b (PBS: $23.67 \pm$ 1.15, Ce6: $13.67 \pm 4.04$, PDMN: $19.33 \pm$ 3.06 and PDMN-Ce6: $10.33 \pm 1.15$ ), and the results implied that the synergetic phototherapy might influence tumor angiogenesis. Taking these results together, PDMN-Ce6 exhibited the highest therapeutic efficiency in destroying tumor vessels and inhibiting tumor growth.

\subsection{Blood biocompatibility and toxicity evaluation}

To further investigate the safety of Ce6, PDMN and PDMN-Ce6 in vivo, mice were chosen and blood was taken after intravenous injection. The samples were analyzed by an automatic animal blood cell analyzer to test for blood indicators including AST, ALT, ALP, BUN and SCr (Fig. 9a and b), and to quantify the amounts of WBC, RBC, HGB and PLT (Fig. S5 $\dagger$ ). Compared with the control group (injected with PBS), no significant differences were found among the groups injected with Ce6, PDMN or PDMN-Ce6. The liver and renal functions of the mice were not impaired after intravenous injection, further demonstrating the biosafety in vivo.

The hemocompatibility of PDMN-Ce6 was further assessed by incubation with RBCs. As shown in Fig. 9c, the hemolytic results of PDMN-Ce6 were lower than $3.5 \%$ at a concentration as high as $8 \mathrm{mg} \mathrm{mL} \mathrm{mL}^{-1}$, compared with negative and positive 

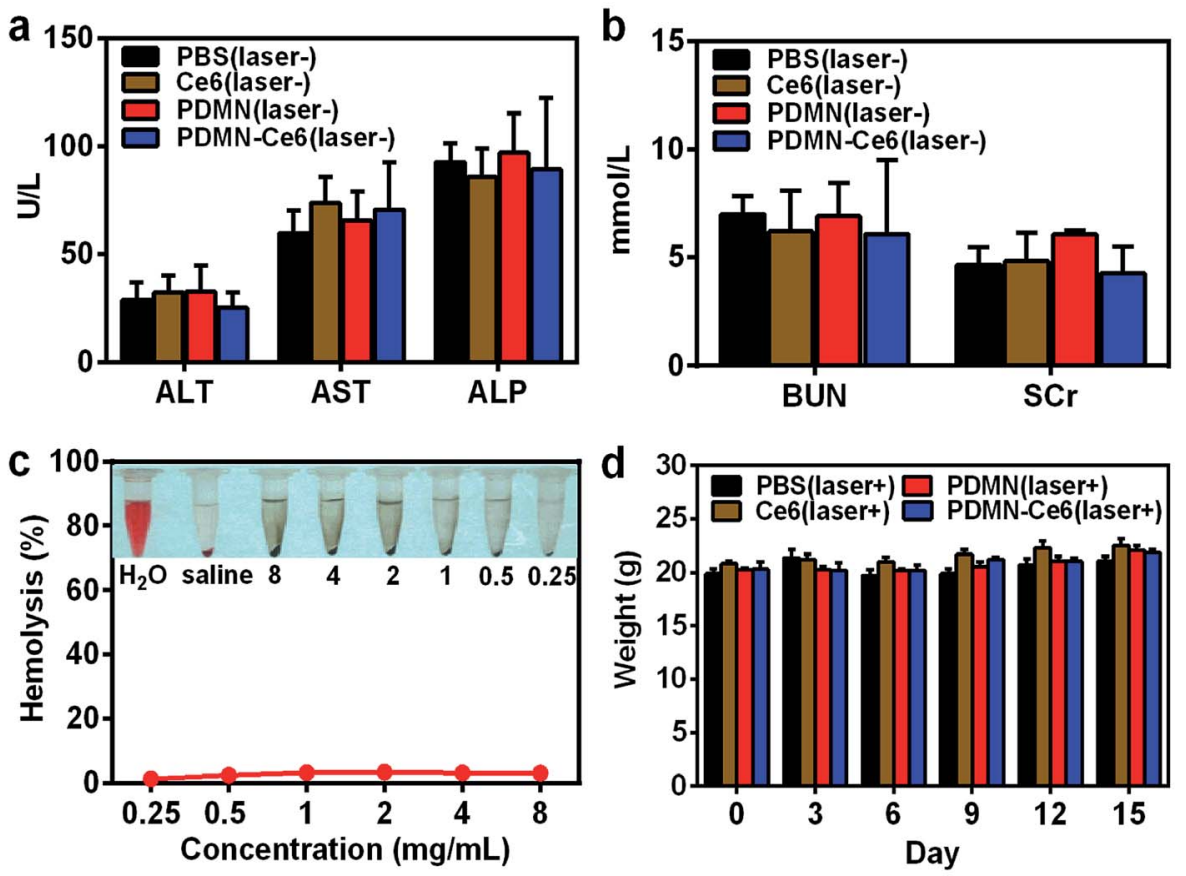

Fig. 9 The blood biochemical indicator analysis after intravenous injection of mice with PBS, Ce6, PDMN or PDMN-Ce6; data were obtained for (a) ALT, AST, ALP and (b) BUN and SCr. (c) The hemolytic reaction of RBCs after incubation with different concentrations of PDMN-Ce6. (d) The changes of body weight for mice in each group after treatment.

controls for the non-hemolytic and hemolytic states. This further proved the excellent biocompatibility of PDMN-Ce6 in the bloodstream.

After the synergistic phototherapy was given to mice treated with PBS, Ce6, PDMN or PDMN-Ce6, vital organs were dissected, and H\&E staining revealed no apparent injury (Fig. S6†). As shown in Fig. 9d, none of the mice from any group showed apparent weight loss during the therapy and observation period. All the results revealed the excellent biocompatibility and low toxicity of PDMN-Ce6, which are very significant for the further clinical transformation of biomimetic nanoparticles.

\section{Conclusion}

In summary, we prepared a PS-loaded biomimetic platform based on melanin nanoparticles (PDMN-Ce6). Via $\pi-\pi$ stacking between PDMN and Ce6, PDMN-Ce6 exhibited a high loading capacity. Based on this efficient and stable loading strategy, we effectively improved the biocompatibility, water-solubility, delivery capacity and tumor-targeting property of Ce6. The precise tumor targeting ability of PDMN-Ce6 was observed by MRI/PAI and was mediated by PDMN; this is helpful for tumor diagnosis and therapy. The imaging guidance revealed that PDMN-Ce6 exhibited superior synergetic PDT and PTT effects in vivo. As an additional result of this synergistic therapy, tumor microvessels were greatly inhibited which is valuable for curbing tumor recurrence. The excellent biocompatibility and minimal toxicity of PDMN-Ce6 in vivo were also demonstrated. Compared to our previous formula based on gold nanoparticles, this nanosystem is biodegradable and easy to synthesize. ${ }^{6,32}$
Therefore, we believe that PDMN-Ce6, as a biomimetic, biocompatible and effective platform, holds great promise for MRI/PAI-guided tumor synergetic phototherapy.

\section{Conflicts of interest}

The authors declare no competing financial interest.

\section{Acknowledgements}

We greatly appreciate financial support from the National Key Basic Research Program of the PRC (2014CB744504), and the National Natural Science Foundation of China (81672102, 81601556, 81871420, 81501588, 81530054, 81501537, $81601555)$.

\section{References}

1 S. B. Brown, E. A. Brown and I. Walker, Lancet Oncol., 2004, 5, 497-508.

2 J. P. Celli, B. Q. Spring, I. Rizvi, C. L. Evans, K. S. Samkoe, S. Verma, B. W. Pogue and T. Hasan, Chem. Rev., 2010, 110, 2795-2838.

3 Z. Zhao, S. Shi, Y. Huang, S. Tang and X. Chen, ACS Appl. Mater. Interfaces, 2014, 6, 8878-8885.

4 Y. Zhang, L. He, J. Wu, K. Wang, J. Wang, W. Dai, A. Yuan, J. Wu and Y. Hu, Biomaterials, 2016, 107, 23-32.

5 Y. N. Konan, R. Gurny and E. Allémann, J. Photochem. Photobiol., B, 2002, 66, 89-106. 
6 S. Wang, P. Huang, L. Nie, R. Xing, D. Liu, Z. Wang, J. Lin, S. Chen, G. Niu, G. Lu and X. Chen, Adv. Mater., 2013, 25, 3055-3061.

7 A. G. Denkova, R. M. de Kruijff and P. Serra-Crespo, Adv. Healthcare Mater., 2018, 7, e1701211.

8 J. F. Lovell, T. W. Liu, J. Chen and G. Zheng, Chem. Rev., 2010, 110, 2839-2857.

9 F. Gao, W. Zheng, L. Gao, P. Cai, R. Liu, Y. Wang, Q. Yuan, Y. Zhao and X. Gao, Adv. Healthcare Mater., 2017, 6, 201601453.

10 C. Wu, D. Li, L. Wang, X. Guan, Y. Tian, H. Yang, S. Li and Y. Liu, Acta Biomater., 2017, 53, 631-642.

11 Q. Sun, Q. You, X. Pang, X. Tan, J. Wang, L. Liu, F. Guo, F. Tan and N. Li, Biomaterials, 2017, 122, 188-200.

12 H. J. Kim, S. M. Lee, K. H. Park, C. H. Mun, Y. B. Park and K. H. Yoo, Biomaterials, 2015, 61, 95-102.

13 S. Sharifi, S. Behzadi, S. Laurent, M. L. Forrest, P. Stroeve and M. Mahmoudi, Chem. Soc. Rev., 2012, 41, 2323-2343.

14 J. Kolosnjaj-Tabi, Y. Javed, L. Lartigue, J. Volatron, D. Elgrabli, I. Marangon, G. Pugliese, B. Caron, A. Figuerola, N. Luciani, T. Pellegrino, D. Alloyeau and F. Gazeau, ACS Nano, 2015, 9, 7925-7939.

15 G. Wan, B. Chen, L. Li, D. Wang, S. Shi, T. Zhang, Y. Wang, L. Zhang and Y. Wang, Biomaterials, 2018, 155, 25-40.

16 Y. Zhao, C. Zhang, L. Gao, X. Yu, J. Lai, D. Lu, R. Bao, Y. Wang, B. Jia, F. Wang and Z. Liu, Cancer Res., 2017, 77, 6021-6032.

17 S. Md, S. Haque, T. Madheswaran, F. Zeeshan, V. S. Meka, A. K. Radhakrishnan and P. Kesharwani, Drug Discovery Today, 2017, 22, 1274-1283.

18 Q. Fan, K. Cheng, X. Hu, X. Ma, R. Zhang, M. Yang, X. Lu, L. Xing, W. Huang, S. S. Gambhir and Z. Cheng, J. Am. Chem. Soc., 2014, 136, 15185-15194.
19 Q. Jiang, Z. Luo, Y. Men, P. Yang, H. Peng, R. Guo, Y. Tian, Z. Pang and W. Yang, Biomaterials, 2017, 143, 29-45.

20 Y. Li, C. Jiang, D. Zhang, Y. Wang, X. Ren, K. Ai, X. Chen and L. Lu, Acta Biomater., 2017, 47, 124-134.

21 R. Zhang, Q. Fan, M. Yang, K. Cheng, X. Lu, L. Zhang, W. Huang and Z. Cheng, Adv. Mater., 2015, 27, 5063-5069.

22 J. Lin, M. Wang, H. Hu, X. Yang, B. Wen, Z. Wang, O. Jacobson, J. Song, G. Zhang, G. Niu, P. Huang and X. Chen, Adv. Mater., 2016, 28, 3273-3279.

23 D. Zhang, M. Wu, Y. Zeng, L. Wu, Q. Wang, X. Han, X. Liu and J. Liu, ACS Appl. Mater. Interfaces, 2015, 7, 8176-8187.

24 D. L. Longo, R. Stefania, C. Callari, R. F. De, R. Rolle, L. Conti, L. Consolino, F. Arena and S. Aime, Adv. Healthcare Mater., 2017, 6, 201600550.

25 M. Yang, Q. Fan, R. Zhang, K. Cheng, J. Yan, D. Pan, X. Ma, A. Lu and Z. Cheng, Biomaterials, 2015, 69, 30-37.

26 W. Xu, J. Sun, L. Li, X. Peng, R. Zhang and B. Wang, Biomater. Sci., 2017, 6, 207-215.

27 Y. Liu, K. Ai, J. Liu, M. Deng, Y. He and L. Lu, Adv. Mater., 2013, 25, 1353-1359.

28 H. Yuan, A. M. Fales and T. Vo-Dinh, J. Am. Chem. Soc., 2012, 134, 11358-11361.

29 R. K. Vartanian and N. Weidner, Lab. Invest., 1995, 73, 844850.

30 H. Xiao, B. Zhu, D. Wang, Y. Pang, L. He, X. Ma, R. Wang, C. Jin, Y. Chen and X. Zhu, Carbon, 2012, 50, 1681-1689.

31 L. Vieira, M. L. Castilho, I. Ferreira, J. Ferreira-Strixino, K. C. Hewitt and L. Raniero, Photodiagn. Photodyn. Ther., 2017, 18, 6-11.

32 W. Liu, Y. Tian, Y. Zhang, K. Liu, S. Zhao, J. Zhang, Y. Su, Y. Zhao, Y. Tang, J. Sun, W. Tian, L. Song, Z. Teng, S. Wang and G. Lu, J. Mater. Chem. B, 2018, 6, 3865-3875. 